\title{
Efficiency in a Search and Matching Model with Endogenous Participation
}

\author{
James Albrecht ${ }^{\mathrm{a}}$ \\ Department of Economics, Georgetown University and IZA \\ Lucas Navarro \\ Department of Economics, ILADES-Universidad Alberto Hurtado \\ Susan Vroman \\ Department of Economics, Georgetown University and IZA
}

\begin{abstract}
We show that in a search/matching model with endogenous participation in which workers are heterogeneous with respect to market productivity, satisfying the Hosios rule leads to excessive vacancy creation.
\end{abstract}

JEL Codes: D8, J6

Keywords: Search, Matching, Efficiency, Participation, Hosios Rule

${ }^{a}$ Corresponding author: Department of Economics, Georgetown University, Washington, DC 20057, USA, Telephone: 202687 6105, FAX: 202687 6102, albrecht@georgetown.edu 
In the standard Pissarides (2000) search/matching model, equilibrium is efficient when wages are determined by Nash bargaining if the worker share of the net surplus of the match equals the elasticity of the matching function with respect to unemployment, i.e., if the Hosios (1990) rule is satisfied. As discussed in Pissarides (2000, Chapter 8), this result holds more generally. In particular, the Hosios rule implements the efficient outcome when workers are heterogenous with respect to their outside options, e.g., their leisure values, and labor force participation is endogenous.

In this note, we also allow for endogenous labor force participation, but assume that workers are heterogeneous with respect to market productiv$i^{1}{ }^{1}$ rather than with respect to leisure values. In this setting, the Hosios condition fails because the participation decision affects not only labor market tightness but also the average productivity of matches. This average productivity effect is not present in the Pissarides version of the model with endogenous labor force participation. In our model, an increase in participation causes average match productivity to fall, but the marginal participant does not internalize this effect. As a result, when wages are determined by the Hosios rule, the labor force participation rate is too high. Equivalently, there is excessive vacancy creation.

To make our point as simply as possible, we consider a one-period version of the model with a continuum of workers of measure one. Each worker chooses between searching for a job (participating) and engaging in home production (not participating). A nonparticipant receives $z$ with certainty, but a participant's expected payoff depends on his or her type and on labor market tightness. Productivity in market work is distributed across workers according to a continuous distribution function $F(y), 0 \leq y \leq 1$ and $F(0)=$ 0 . All participants search and find a job with probability $m(\theta)$, where $\theta$ is market tightness. ${ }^{2}$ A worker of type $y$ who finds a job gets a fraction $\beta$ of the output that he or she produces; a worker who participates but fails to find a job gets a payoff that is normalized to zero. The expected payoff of a participant of type $y$ is thus $m(\theta) \beta y$. A worker participates iff $m(\theta) \beta y \geq z$,

\footnotetext{
${ }^{1}$ A similar issue arises in the Albrecht, Navarro and Vroman (2009) model of developing economy labor markets with an informal sector in which workers have different formalsector productivities.

${ }^{2}$ As in Pissarides (2000), the matching function $M(v, u)$ is assumed to have constant returns to scale so it can be written as $m(\theta) u$. We assume that $m(\theta)$ is independent of $y$; i.e., all participants have an equal chance of finding a job. Our model can be thought of as one in which employers search sequentially for candidates, e.g., an employer hires the first worker who applies for the job. Villena-Roldán (2008) considers a model of nonsequential employer search in which a worker's chance of getting a job depends on his or her productivity.
} 
so there is a cutoff value of $y$,

$$
y^{*}=\frac{z}{\beta m(\theta)}
$$

such that all workers with $y \geq y^{*}$ participate; the remaining workers are nonparticipants. Call this function $y^{*}=h(\theta)$, and note that

$$
h^{\prime}(\theta)=-\frac{m^{\prime}(\theta)}{m(\theta)} y^{*}<0
$$

The participation rate is $1-F\left(y^{*}\right)$, so labor market tightness is

$$
\theta=\frac{v}{1-F\left(y^{*}\right)}=\frac{v}{1-F(h(\theta))}
$$

where $v$ is the measure of vacancy creation. Differentiating implicitly with respect to $v$,

$$
\frac{d \theta}{d v}=\frac{\partial \theta}{\partial v}+\frac{\partial \theta}{\partial y^{*}} h^{\prime}(\theta) \frac{d \theta}{d v}
$$

where

$$
\begin{aligned}
\frac{\partial \theta}{\partial v} & =\frac{1}{1-F\left(y^{*}\right)} \\
\frac{\partial \theta}{\partial y^{*}} & =\frac{\theta f\left(y^{*}\right)}{1-F\left(y^{*}\right)} .
\end{aligned}
$$

Note that $d \theta / d v>0$.

Equilibrium requires that workers optimally choose whether to participate or not and that vacancies are created until the value of a vacancy equals zero. The value of a vacancy is

$$
V=-c+\frac{m(\theta)}{\theta}(1-\beta) \int_{y^{*}}^{1} \frac{y f(y)}{1-F\left(y^{*}\right)} d y
$$

where $c$ is the cost to open the vacancy, $m(\theta) / \theta$ is the probability that the vacancy hires a worker, and $y^{*}$ is determined by worker choice. Setting this value to zero gives

$$
\frac{m(\theta)}{\theta}(1-\beta) \int_{y^{*}}^{1} \frac{y f(y)}{1-F\left(y^{*}\right)} d y=c .
$$

Equations (1) and (3) can be solved for the equilibrium values of $\theta$ and $y^{*}$. 
Next we consider the efficiency problem. The social planner chooses $v$ to maximize

$$
\begin{aligned}
\Omega & =z F\left(y^{*}\right)+\left(1-F\left(y^{*}\right)\right) m(\theta) \int_{y^{*}}^{1} \frac{y f(y)}{1-F\left(y^{*}\right)} d y-c v \\
& =z F\left(y^{*}\right)+m(\theta) \int_{y^{*}}^{1} y f(y) d y-c v,
\end{aligned}
$$

taking into account that workers choose whether or not to participate. The first term on the RHS is the value for nonparticipants, the second term is the value of market output, and the third term subtracts the costs of vacancy creation. The derivative of the social planner's objective with respect to $v$ is

$$
\begin{aligned}
\frac{d \Omega}{d v} & =\left(z-m(\theta) y^{*}\right) f\left(y^{*}\right) h^{\prime}(\theta) \frac{d \theta}{d v}+m^{\prime}(\theta) \int_{y^{*}}^{1} y f(y) d y \frac{d \theta}{d v}-c \\
& =\left(z-m(\theta) y^{*}\right) f\left(y^{*}\right) h^{\prime}(\theta) \frac{d \theta}{d v}+m^{\prime}(\theta) \int_{y^{*}}^{1} y f(y) d y\left(\frac{\partial \theta}{\partial v}+\frac{\partial \theta}{\partial y^{*}} h^{\prime}(\theta) \frac{d \theta}{d v}\right)-c
\end{aligned}
$$

Substituting for $\frac{\partial \theta}{\partial v}$ and $\frac{\partial \theta}{\partial y^{*}}$ and rearranging gives

$$
\begin{aligned}
\frac{d \Omega}{d v}= & \left(z-m(\theta) y^{*}+\theta m^{\prime}(\theta) \int_{y^{*}}^{1} \frac{y f(y)}{1-F\left(y^{*}\right)} d y\right) f\left(y^{*}\right) h^{\prime}(\theta) \frac{d \theta}{d v} \\
& +m^{\prime}(\theta) \int_{y^{*}}^{1} \frac{y f(y)}{1-F\left(y^{*}\right)} d y-c .
\end{aligned}
$$

The Hosios rule sets the worker share of the net surplus equal to the elasticity of the matching function with respect to unemployment. ${ }^{3}$ It can be written as

$$
1-\beta=\frac{\theta m^{\prime}(\theta)}{m(\theta)}
$$

If this condition holds, then

$$
m^{\prime}(\theta) \int_{y^{*}}^{1} \frac{y f(y)}{1-F\left(y^{*}\right)} d y=\frac{m(\theta)}{\theta}(1-\beta) \int_{y^{*}}^{1} \frac{y f(y)}{1-F\left(y^{*}\right)} d y,
$$

so from equation (3),

$$
m^{\prime}(\theta) \int_{y^{*}}^{1} \frac{y f(y)}{1-F\left(y^{*}\right)} d y=c
$$

\footnotetext{
${ }^{3}$ As discussed in footnote 2 , the matching function is $m(\theta) u$.
} 
and the final two terms in equation (4) cancel. That is,

$$
\frac{d \Omega}{d v}=\left(z-m(\theta) y^{*}+\theta m^{\prime}(\theta) \int_{y^{*}}^{1} \frac{y f(y)}{1-F\left(y^{*}\right)} d y\right) f\left(y^{*}\right) h^{\prime}(\theta) \frac{d \theta}{d v} .
$$

Note that we are evaluating $d \Omega / d v$ at the equilibrium level of vacancy creation when $\beta$ equals the Hosios value. If $d \Omega / d v>0$ at the "Hosios level" of vacancy creation, there is not enough vacancy creation in equilibrium; if $d \Omega / d v<0$, too many vacancies are being set up. ${ }^{4}$ Since $f\left(y^{*}\right) h^{\prime}(\theta) \frac{d \theta}{d v}<0$, the sign of $d \Omega / d v$ at the Hosios level of $v$ is the opposite of that of the term in parentheses in equation (5). The net output of the marginal participant is $m(\theta) y^{*}-z$. The marginal participant also reduces the average productivity of matches in the market sector. This is reflected in the term $\theta m^{\prime}(\theta) \int_{y^{*}}^{1} \frac{y f(y)}{1-F\left(y^{*}\right)} d y$. If workers were homogeneous with respect to market productivity, then this term would be independent of $y^{*}$; i.e., participation would have no effect on average productivity.

To sign $d \Omega / d v$, note that

$$
z-m(\theta) y^{*}=-(1-\beta) m(\theta) y^{*}
$$

and, by the Hosios condition,

$$
\theta m^{\prime}(\theta) \int_{y^{*}}^{1} \frac{y f(y)}{1-F\left(y^{*}\right)} d y=(1-\beta) m(\theta) \int_{y^{*}}^{1} \frac{y f(y)}{1-F\left(y^{*}\right)} d y .
$$

We then have

$$
\begin{aligned}
\frac{d \Omega}{d v} & =\left(-(1-\beta) m(\theta) y^{*}+(1-\beta) m(\theta) \int_{y^{*}}^{1} \frac{y f(y)}{1-F\left(y^{*}\right)} d y\right) f\left(y^{*}\right) h^{\prime}(\theta) \frac{d \theta}{d v} \\
& =(1-\beta) m(\theta)\left(\int_{y^{*}}^{1} \frac{\left(y-y^{*}\right) f(y)}{1-F\left(y^{*}\right)} d y\right) f\left(y^{*}\right) h^{\prime}(\theta) \frac{d \theta}{d v}<0 .
\end{aligned}
$$

We have thus shown that when $\beta$ equals the Hosios value, too many vacancies are created in equilibrium. Equivalently, $y^{*}$ is too low - the rate of labor force participation is inefficiently high.

\footnotetext{
${ }^{4}$ When $z=0$, the equilibrium level of vacancy creation is efficient, i.e., $d \Omega / d v=0$. The reason is that when $z=0$, all workers participate, i.e., $y^{*}=0$, which in turn implies $h^{\prime}(\theta)=0$.
} 


\section{References}

[1] Albrecht, J., L. Navarro and S. Vroman, 2009, The Effects of Labour Market Policies in an Economy with an Informal Sector, The Economic Journal, 119, 1105-1129.

[2] Hosios, A., 1990, On the Efficiency of Matching and Related Models of Search and Unemployment, Review of Economic Studies, 57, 279-98.

[3] Pissarides, C. 2000, Equilibrium Unemployment Theory, 2nd edition, MIT Press, Cambridge, Mass.

[4] Villena-Roldán, B., 2008, Aggregate Implications of Employer Search and Recruiting Selection, mimeo, University of Rochester. 